\title{
Plasma Surface Modification of Polymer Backsheets: Origins of Future Interfacial Barrier/Backsheet Failure
}

J.W. Pankow and S.H. Glick

Presented at the 2005 DOE Solar Energy Technologies Program Review Meeting November 7-10, 2005 Denver, Colorado

Conference Paper NREL/CP-520-38965

November 2005 


\section{NOTICE}

The submitted manuscript has been offered by an employee of the Midwest Research Institute (MRI), a contractor of the US Government under Contract No. DE-AC36-99G010337. Accordingly, the US Government and MRI retain a nonexclusive royalty-free license to publish or reproduce the published form of this contribution, or allow others to do so, for US Government purposes.

This report was prepared as an account of work sponsored by an agency of the United States government. Neither the United States government nor any agency thereof, nor any of their employees, makes any warranty, express or implied, or assumes any legal liability or responsibility for the accuracy, completeness, or usefulness of any information, apparatus, product, or process disclosed, or represents that its use would not infringe privately owned rights. Reference herein to any specific commercial product, process, or service by trade name, trademark, manufacturer, or otherwise does not necessarily constitute or imply its endorsement, recommendation, or favoring by the United States government or any agency thereof. The views and opinions of authors expressed herein do not necessarily state or reflect those of the United States government or any agency thereof.

Available electronically at http://www.osti.gov/bridge

Available for a processing fee to U.S. Department of Energy and its contractors, in paper, from:

U.S. Department of Energy

Office of Scientific and Technical Information

P.O. Box 62

Oak Ridge, TN 37831-0062

phone: 865.576.8401

fax: 865.576 .5728

email: mailto:reports@adonis.osti.gov

Available for sale to the public, in paper, from:

U.S. Department of Commerce

National Technical Information Service

5285 Port Royal Road

Springfield, VA 22161

phone: 800.553 .6847

fax: 703.605.6900

email: orders@ntis.fedworld.gov

online ordering: http://www.ntis.gov/ordering.htm 


\title{
Plasma Surface Modification of Polymer Backsheets: Origins of Future Interfacial Barrier/Backsheet Failure
}

\author{
Joel W. Pankow, ${ }^{1}$ Stephen H. Glick \\ ${ }^{1}$ National Renewable Energy Laboratory, Golden, Colorado, joel_pankow@nrel.gov
}

\begin{abstract}
Flexible polymer substrates coated with inorganic oxide moisture barriers are a potential replacement for glass backsheets in thin film PV modules. Silicon oxynitride $\left(\mathrm{SiO}_{x} \mathrm{~N}_{y}\right)$ deposited by PECVD on polyethylene terephthalate (PET) represents one potential new backsheet candidate. Barrier deposition runs at NREL have typically included a nitrogen-rich plasma pretreatment prior to actual barrier deposition with the intention of cleaning the PET surface as well as enhancing adhesion of the $\mathrm{SiO}_{x} \mathrm{~N}_{\mathrm{y}}$ barrier film to PET; however, test coupons of PET/barrier/EVA/TPE failed after damp heat exposure. PET substrates exposed to plasma conditions similar to those used in pre-treatment were examined by X-ray photoelectron spectroscopy (XPS) to reveal new low molecular weight PET fragments are created which are volatile upon heating and water soluble. Failure analysis of the coupons determined that the moisture barrier is, in fact, transferred to the encapsulant side.
\end{abstract}

\section{Objectives}

The reliability of any PV module is highly dependent on the actual packaging components used and the importance of reliability is stressed throughout the Solar Program Multi-Year Technical Plan. Glass is a key packaging component of thin film PV modules and is used as both the frontsheet and backsheet material. Disadvantages of glass such as weight, cost, and a propensity towards breakage both from edge pinching as well as handling have been motivating factors behind efforts to identify alternative backsheet (and potentially frontsheet) materials. Polymer films are one alternative and, in contrast to glass, weigh less, are less costly, and have better handling characteristics. However, unlike glass, polymer films are not inherently impervious to moisture and an additional moisture barrier must be applied to any polymer film candidate under consideration. The goal of this work has been to explore the feasibility of one particular barrier/polymer backsheet combination $\mathrm{SiO}_{x} \mathrm{~N}_{y}$ on PET. XPS was utilized to examine a variety of issues discussed in this paper with results that are guiding further research focused on the development of a viable barrier coated polymer backsheet material.

\section{Technical Approach}

DuPont Melinex® ST504 PET film was used for these studies. This product contains one side which has been treated by the manufacturer for ink adhesion and one side which is untreated. For the barrier depositions discussed here, only the untreated, pure PET side was coated. A five chamber, Pernicka PECVD system was used for the barrier depositions using a gas mixture of silane, oxygen, nitrous oxide and nitrogen in proportions which were varied throughout the deposition. Plasma pretreatment is carried out in the same chamber where subsequent barrier deposition occurs. For control studies of only the plasma pretreatment step, the Pernicka chamber was fitted with a glove bag which was mounted over the entry lock door using a custom mounting flange in order to allow for plasma treated PET samples to be sealed in glass vials under a nitrogen environment. Finally, a Physical Electronics 5600 XPS instrument using monochromatic $\mathrm{Al} \mathrm{Ka}$ radiation was used to evaluate both plasma treated PET as well as barrier coated PET samples. Because both the polymer PET film and $\mathrm{SiO}_{x} \mathrm{~N}_{\mathrm{y}}$ barrier film are insulating in nature, optimization of electron flood gun parameters and other instrumental conditions were required to minimize charging effects. The XPS instrument is part of a cluster tool also featuring a glove box such that sealed vials containing plasma treated PET samples could be opened, mounted, and transported to the XPS instrument all under inert or vacuum conditions.

\section{Results and Accomplishments}

\subsection{Effects of Plasma Pre-Treatment}

The pure PET side of ST504 was exposed to plasma treatment at $60 \mathrm{~W}$ in $500 \mathrm{sscm} \mathrm{N} \mathrm{N}_{2}$ and 100 sscm $\mathrm{N}_{2} \mathrm{O}\left(14 \% \mathrm{~N}_{2} \mathrm{O}\right.$ in $\left.\mathrm{N}_{2}\right)$ for 10 minutes. Samples were sealed under inert nitrogen conditions in the glove bag and examined by XPS as discussed above. Survey scans of the surface indicated the presence of nearly 5 atomic percent nitrogen in addition to expected carbon and oxygen. Figure 1 illustrates the high resolution $\mathrm{C} 1 \mathrm{~s}$ scan for the various PET samples and the PET molecular structure. The reference spectrum for PET shows three well resolved peaks and a shake-up peak. From low to high binding energy, these peaks are assigned to aromatic carbons, ethylene carbons, carbonyl carbons, and a shake-up peak. The first three peaks are found in nearly a 3:1:1 ratio consistent with the atomic fractions of the various carbon species in the molecule. After plasma treatment, spectra subtraction shows a reduction in the concentration of all three carbon functionalities. Peak intensity above the horizontal zero counts line indicates new, unique species present on the surface of the plasma treated PET. At least three new functionalities can be identified - namely terminal carbonyl, terminal carboxylic acid, and 
phenolic $-\mathrm{OH}$ groups $^{1}$. All these functionalities are consistent with a chain scission mechanism of polymeric PET which creates low molecular weight fragments with new terminal end group functionalities.

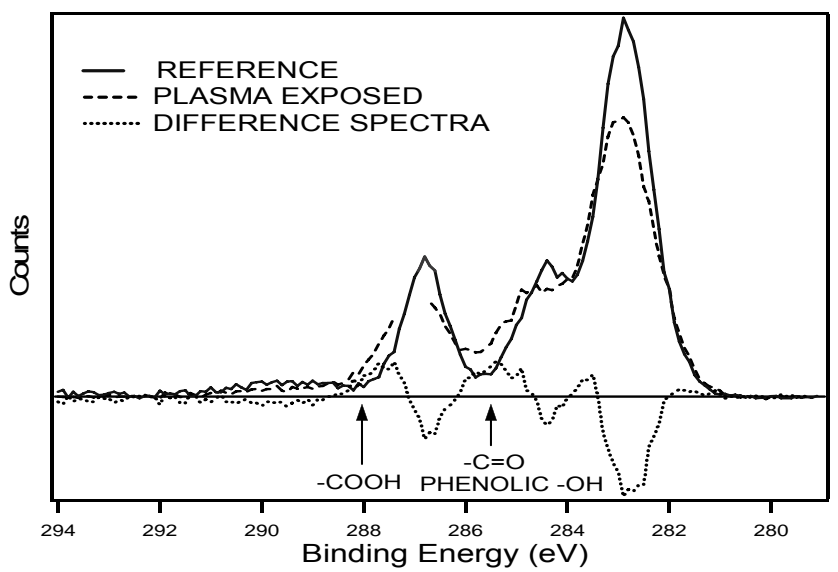

Fig.1. XPS C1s spectra of PET samples

\subsection{Thermal desorption XPS of plasma treated PET}

The plasma treated PET sample was subsequently heated in the XPS instrument by ramping substrate temperature with periodic scanning of the $\mathrm{C} 1 \mathrm{~s}, \mathrm{O} 1 \mathrm{~s}$ and $\mathrm{N} 1 \mathrm{~s}$ regions. At approximately $70^{\circ} \mathrm{C}$, nitrogen content began to decrease and the $\mathrm{C} 1 \mathrm{~s}$ and $\mathrm{O} 1 \mathrm{~s}$ regions progressively began to resemble those for pure PET. By approximately $145^{\circ} \mathrm{C}$, nitrogen was not detected and the $\mathrm{C} 1 \mathrm{~s}$ and $\mathrm{O} 1 \mathrm{~s}$ regions appeared exactly as for pure PET. In other experiments, plasma treated PET was immersed in pure deionized water for several minutes followed by XPS examination. Again, nitrogen content decreased and the $\mathrm{C} 1 \mathrm{~s}$ and $\mathrm{O} 1 \mathrm{~s}$ regions began to resemble pure $P E T$.

3.3 Interfacial failure analysis of PET/barrier/EVA/TPE

Several $\mathrm{SiO}_{x} \mathrm{~N}_{y}$ coated PET films were laminated to EVA using TPE (Tedlar-polyester-EVA) in the following construction: PET/barrier/EVA/TPE with the EVA side of TPE in contact with the bulk film EVA. Although initial adhesion was promising, the coupons readily delaminated after about $100 \mathrm{hrs}$ of damp heat $\left(85^{\circ} \mathrm{C} / 85 \% \mathrm{RH}\right)$ exposure. XPS examination of the PET side showed approximately 2 atomic percent nitrogen and 1 to 3 atomic percent silicon. Levels of carbon and oxygen were nearly those of pure PET. Depth profiling quickly removed detectable levels of both nitrogen and silicon leaving only carbon and oxygen. For the mated EVA side, approximately 2 atomic percent nitrogen and 10 to 16 atomic percent silicon was detected with the balance consisting of carbon and oxygen. Nitrogen was readily removed within a few minutes of depth profiling $(<100 \AA)$ to leave less than 10 atomic percent carbon with silicon and oxygen providing the balance in nearly a $2: 1$ ratio.

\subsection{XPS depth profiling of barrier coatings on PET}

In order to better interpret the interfacial failure analysis results, retains of the barrier films used in the construction of the coupons were depth profiled (see
Fig. 2). For these films, a plasma pretreatment preceded the actual deposition. During $\mathrm{SiO}_{x} \mathrm{~N}_{\mathrm{y}}$ deposition, nitrous oxide content in the PECVD gas blend was increased at the expense of oxygen gas content as deposition proceeded from Phase 1 at the PET interface through Phase 3 at the exterior of the barrier film.

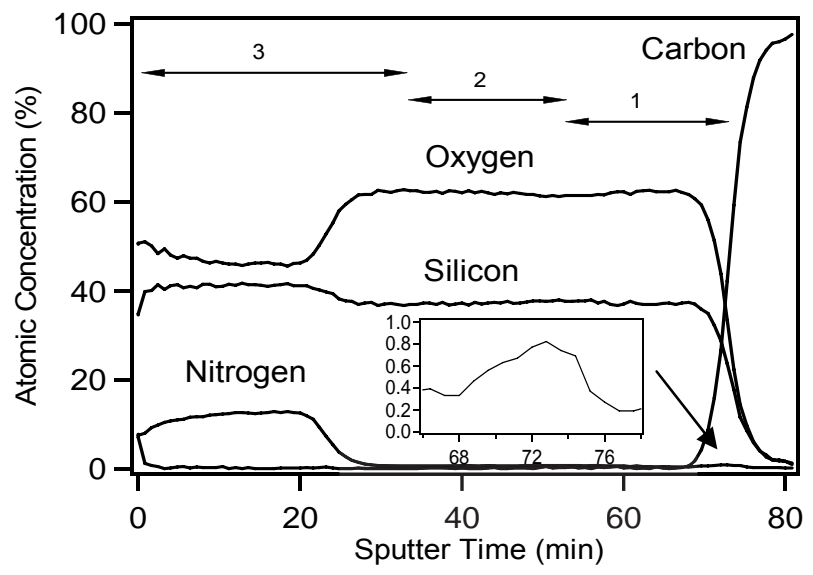

Fig. 2. XPS depth profile of barrier film on PET

Despite nitrogen content in the gas blend during all three phases of the deposition, trace to no detectable nitrogen is found for the first two phases. In addition, nitrogen incorporation at levels approaching 1 atomic percent is found at the PET/barrier interface (Fig. 2 inset).

\section{Conclusions}

Control experiments involving plasma pretreatment of PET substrates demonstrate that plasma exposure induces chain scission of the PET molecular structure resulting in formation of low molecular weight fragments. These fragments appear to be volatile upon heating as well as water soluble. The fragments are loosely bound to underlying intact PET polymer chains and create the potential for interfacial failure. Plasma pretreatment of PET prior to PECVD $\mathrm{SiO}_{x} \mathrm{~N}_{\mathrm{y}}$ barrier deposition results in retention of these species at the PET/barrier interface as illustrated in the depth profile. Detection of low levels of nitrogen on the EVA side of delaminated coupons along with silicon to oxygen ratios matching those found for Phase 3 in the latter part of barrier depth profiles is consistent with interfacial failure at the PET/barrier interface resulting in barrier transfer to the EVA side of such coupons.

\section{ACKNOWLEDGEMENTS}

The NREL work was performed under DOE contract DE-AC36-99-G010337. Gary Jorgensen and Kent Terwilliger are acknowledged for their contributions on barrier test coupon lamination and damp heat testing. 


\section{REFERENCES}

${ }^{1}$ D.Briggs, Surface analysis of polymers by XPS and static SIMS, (Cambridge University Press, New York, 1998). 


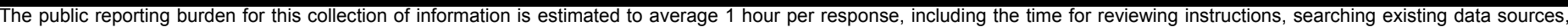

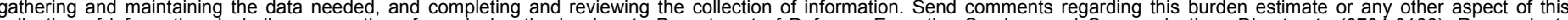

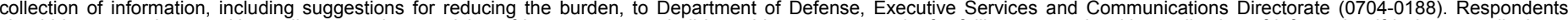

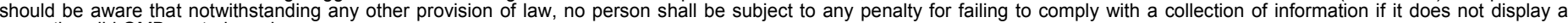
currently valid OMB control number.

PLEASE DO NOT RETURN YOUR FORM TO THE ABOVE ORGANIZATION.

\section{REPORT DATE (DD-MM-YYYY) \\ November 2005}

4. TITLE AND SUBTITLE

Plasma Surface Modification of Polymer Backsheets: Origins of

Future Interfacial Barrier/Backsheet Failure
3. DATES COVERED (From - To)

5a. CONTRACT NUMBER

DE-AC36-99-GO10337

5b. GRANT NUMBER

5c. PROGRAM ELEMENT NUMBER

5d. PROJECT NUMBER

NREL/CP-520-38965

5e. TASK NUMBER

PVA6.3301

5f. WORK UNIT NUMBER
7. PERFORMING ORGANIZATION NAME(S) AND ADDRESS(ES)

National Renewable Energy Laboratory

1617 Cole Blvd.

Golden, CO 80401-3393
8. PERFORMING ORGANIZATION

REPORT NUMBER

NREL/CP-520-38965

9. SPONSORING/MONITORING AGENCY NAME(S) AND ADDRESS(ES)

10. SPONSOR/MONITOR'S ACRONYM(S) NREL

11. SPONSORING/MONITORING AGENCY REPORT NUMBER

\section{DISTRIBUTION AVAILABILITY STATEMENT}

National Technical Information Service

U.S. Department of Commerce

5285 Port Royal Road

Springfield, VA 22161

\section{SUPPLEMENTARY NOTES}

\section{ABSTRACT (Maximum 200 Words)}

Flexible polymer substrates coated with inorganic oxide moisture barriers are a potential replacement for glass backsheets in thin film PV modules. Silicon oxynitride $\left(\mathrm{SiO}_{\mathrm{x}} \mathrm{N}_{\mathrm{y}}\right)$ deposited by PECVD on polyethylene terephthalate (PET) represents one potential new backsheet candidate. Barrier deposition runs at NREL have typically included a nitrogen-rich plasma pretreatment prior to actual barrier deposition with the intention of cleaning the PET surface as well as enhancing adhesion of the $\mathrm{SiO} \mathrm{N}_{\mathrm{y}}$ barrier film to PET; however, test coupons of PET/barrier/EVA/TPE failed after damp heat exposure. PET substrates exposed to plasma conditions similar to those used in pre-treatment were examined by X-ray photoelectron spectroscopy (XPS) to reveal new low molecular weight PET fragments are created which are volatile upon heating and water soluble. Failure analysis of the coupons determined that the moisture barrier is, in fact, transferred to the encapsulant side.

\section{SUBJECT TERMS}

Photovoltaics; solar; polymer substrates; plasma; PV; NREL

\begin{tabular}{l}
\hline 16. SECURITY CLASSIFICATION OF: \\
\begin{tabular}{|l|l|l|}
\hline a. REPORT & b. ABSTRACT & c. THIS PAGE \\
Unclassified & Unclassified & Unclassified \\
& & \\
\hline
\end{tabular} \\
\hline
\end{tabular}

17. LIMITATION
OF ABSTRACT
UL

18. NUMBER
OF PAGES

19a. NAME OF RESPONSIBLE PERSON

19b. TELEPONE NUMBER (Include area code) 